\title{
Distribution of diurnal land surface temperature in Yogyakarta urban area
}

\author{
Alfiatun N. K., Dwi Setyo Aji
}

Alfiatun N. K., Dwi Setyo Aji, "Distribution of diurnal land surface temperature in Yogyakarta urban area," Proc. SPIE 11311, Sixth Geoinformation Science Symposium, 1131109 (21 November 2019); doi: 10.1117/12.2548980

SPIE Event: Sixth Geoinformation Science Symposium, 2019, Yogyakarta, Indonesia 


\title{
Distribution of Land Surface Temperature In Yogyakarta Urban Area
}

\author{
Alfiatun $\mathrm{NK}^{* \mathrm{a}}$, Dwi Setyo Aji ${ }^{\mathrm{a}}$ \\ ${ }^{a}$ Diploma of Remote Sensing and Geographic Information System Study Program, \\ Vocational School Gadjah Mada University \\ *Alfiatunnur.k@ugm.ac.id
}

\begin{abstract}
Yogyakarta urban area has grown throughout the year as the course of migration and its attraction to tourists and students resulting in the high demand of living space which leads to the increment of the built-up area such as hotels and other supporting-tourism-activity accommodation, so-called urban sprawl. The increase of paved-surface causes the increase of land surface temperature (LST), which may impact to micro-climate in the urban area with adverse consequences, for instance, erratic rainfall and rainstorm in the urban area. Consequently, it triggers new future problems. Therefore, it is necessary to study LST to perceive the state of temperature change in the study area as a preliminary assessment in studying urban climate.

This paper attempts to present the distribution of Land Surface Temperature (LST) in Yogyakarta urban area, extracted from remotely-sensed Landsat 8 image acquired from a two-year image. Before the extraction, several variables are incorporated such as Normalized Difference Vegetation Index (NDVI) to calculate emissivity, as well as atmospheric correction parameter transmissivity, upwelling and downwelling radiance. The reflectance values are also corrected to obtain NDVI. Land surface temperature extracted according to the procedures: conversion of the digital number of Landsat image to radiance, correction of radiance value, conversion of the corrected radiance value to brightness temperature, then brightness temperature to land surface temperature. The extracted temperature map then presented into $5^{\circ} \mathrm{C}$ interval.

Consecutively, the two-year of temperature maps are then analyzed to obtain the difference of its spatial distribution. The expected result is the expanding high-temperature distribution in the urban area. The result shows there is an increase in the average land surface temperature by $1,5^{\circ} \mathrm{C}$ from two different images, 2014 and 2018 . The majority value of temperature is between $30-40^{\circ} \mathrm{C}$, dominated with the built-up area. Two image shows that the respective area spread from $54 \%$ to $70 \%$.
\end{abstract}

Keywords: Diurnal, LST, Landsat, Urban

\section{INTRODUCTION}

The urban area tends to expand in parts of the world as the increment of population migration to an urban area. The expansion of urban area tends to alter the urban landscape that the proportion of built-up area dominated the space as the demand for economic activities and space to live. Yogyakarta has attracted tourists and students recently, which contributes to the more built-up area to accommodates the activities, for instance, student housing, restaurants and hotels. As a consequence, Yogyakarta city expanded as the growth of the urban area as the implication of these demands.

The study of urban growth of Yogyakarta city had been studied by Giyarsih (2010). The growth of the urban area of Yogyakarta through a long process other than short one, the spatial distribution of the transformation influenced by street connections and growth areas. Moreover, the growth of Yogyakarta in terms of the expansion of urban area according to the finding of Divigalpitiya, P \& Handayani, K. N (2015) shows that Yogyakarta city experienced outward expansion commenced with small urban patches then merged to form larger urban patches. The visible expansion mainly through the period from 2002 to 2013.

As the tendency of urban growth follows the increase of paved-surface/ built-up area, it affects the state of urban climate. Urban microclimate associated with effects of urban landscape design had studied in Yang, Lin, \& Li (2018). One of the findings is the shade trees combined with grass can reduce air temperature by $0.75 \mathrm{oC}$. Therefore, the monitor of temperature in the urban area becomes vital as the temperature is one of the elements of climate. The change of temperature

Sixth Geoinformation Science Symposium, edited by Sandy Budi Wibowo, Andi B. Rimba

Stuart Phinn, Ammar A. Aziz, Proc. of SPIE, Vol. 11311, 1131109 • () 2019 SPIE

CCC code: $0277-786 \mathrm{X} / 19 / \$ 21 \cdot$ doi: $10.1117 / 12.2548980$ 
has indirect impacts on urban climate, for instance, erratic rainfall and rainstorm, and other hydro-meteorological hazards. Furthermore, the importance of temperature monitoring has been increasing as the concern in global warming.

The use of Remote sensing technique become possible to extract phenomena without direct contact with objects (Lillesand $\&$ Kieffer, 2002). Remote sensing imagery has been widely used as input to monitor the state of temperature. Remote sensing has the advantage of its efficacy and efficiency due to the less fieldwork and affordability comparing to field measurement.This image records the earth's surface every 16 days, making it possible to use it for monitoring an area regularly. Each pixel of Landsat 8 multispectral image represents $30 \mathrm{~m}$ x $30 \mathrm{~m}$, with 12 bits of radiometric resolution. Landsat 8 consists of two instruments, namely Operational Land Imager (OLI) and Thermal Infrared Sensor (TIRS) which provides a wide range of spatial scope and decades of temporal data assuring to give beneficial inputs for temperature monitoring.

This paper attempts to demonstrate a sequence to extract land surface temperature (LST) information from Landsat 8 thermal band from two different years, on 2014 and 2018, in Yogyakarta urban area. This research emphasizes on the methodology which to provide a step-by-step guide for future monitoring of temperature involving longer time series data.

\section{STUDY AREA}

Special Region of Yogyakarta is located in the southern part of Java Island and has a direct border to the Hindia Ocean (Figures 1). The capital city of Yogyakarta has $32,1 \mathrm{~km} 2$ of area and located in the centre of the province. It is famous for its culture and education and tourist destination. Although it is known as the smallest province in Java island, Yogyakarta is one of the most livable cities in Indonesia (IAP,2014). Statistic Agency of Yogyakarta reported there had been growing in population. The average population density is 13,007 inhabitants $/ \mathrm{km}^{2}$. The urban area of Yogyakarta has been growing and encompasses 26 districts in total. The average rainfall in Yogyakarta is 2.012 $\mathrm{mm} /$ years. The average air humidity is quite high, ranges from $81-90 \%$, where the lowest occurs in August and September, which is $81 \%$. The average temperatures around $27^{\circ} \mathrm{C}$. The dry season begins in April until October.

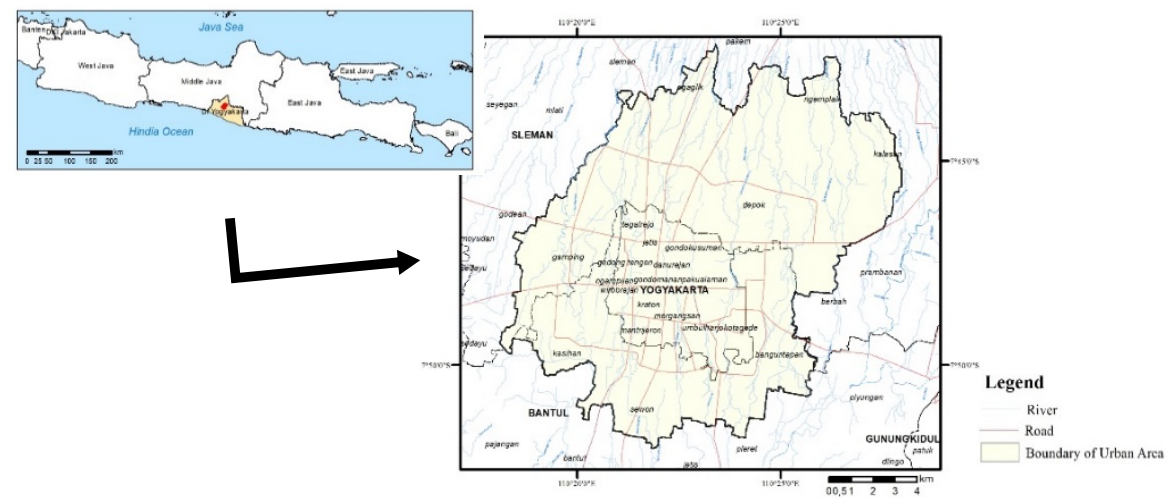

Figure 1. Map of Yogyakarta's Urban Area

\section{DATA AND METHODOLOGY}

Landsat 8 Thermal Infrared band (TIR) was adopted to extract land surface temperature (LST) information in Yogyakarta urban area. Landsat 8 TIR images were acquired from two different dates in the dry season, in August 2014 and May 2018. Due to the LST extraction process, atmospheric correction parameters obtained from the website (https://atmcorr.gsfc.nasa.gov/) such as transmissivity, upwelling, and downwelling radiance (Figure 3). Normalized Difference Vegetation Index (NDVI) value also extracted to determine emissivity value before LST extraction. Atmospheric correction was also applied to obtain reflectance value to extract NDVI. The required parameters to extract temperature were obtained from image metadata. 


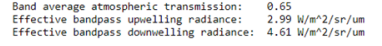

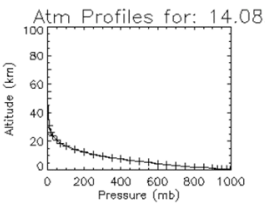

Rel Humidity (s) 80

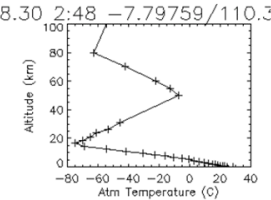

$t=0.65$
$L u=2.99$
$L d=4.61$

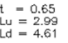

(a)
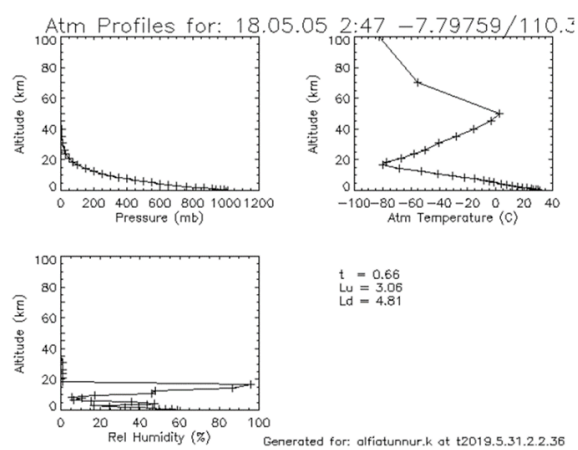

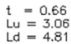

Figure 3. Atmospheric Correction Parameter for (a) 2014 and (b) 2018 Landsat 8 Images

Generally, land surface temperature extraction from Landsat 8 TIR band requires several following procedures:

1. Conversion pixel value/ digital number (DN) to radiance (Equation 1), correction of radiance value (atmospheric correction) using Equation 4

2. Conversion of the atmospheric-corrected radiance value to brightness temperature using Equation 2

3. Conversion of brightness temperature to land surface temperature using Equation 3

Reflectance value of NDVI was corrected using Equation 6, 7, and 8.

Emissivity was calculated using Equation 5

The equations below were applied to extract land surface temperature from Landsat 8 TIR image.

Digital Number (DN) to Spectral Radiance:

$$
L_{\lambda}=M_{L} Q_{c a l}+A_{L}
$$

$\mathrm{L}_{\lambda} \quad=$ Top of Atmosphere spectral radiance $\left(\right.$ Watts $\left./\left(\mathrm{m}^{2} * \operatorname{srad}^{*} \mu \mathrm{m}\right)\right)$

$\mathrm{M}_{\mathrm{L}}=$ Multiplicative scale*

$\mathrm{A}_{\mathrm{L}} \quad=$ Additive value*

$\mathrm{Q}_{\mathrm{cal}}=$ Digital Number $(\mathrm{DN})$

*from metadata

Spectral radiance to brightness temperature was calculated using equation mentioned in McCarville, et. Al. (2011):

$$
T_{B}=\frac{K_{2}}{\ln \left(\frac{K_{1}}{L_{\lambda}}+1\right)}
$$

$\mathrm{T}_{\mathrm{B}}=$ Brightness temperature $(\mathrm{K})$

$\mathrm{L}_{\lambda}=$ Spectral radiance $\left(\right.$ Watts $\left./\left(\mathrm{m}^{2 *} \operatorname{srad}^{*} \mu \mathrm{m}\right)\right)$

$\mathrm{K}_{1}, \mathrm{~K}_{2}=$ Constant value (from metadata)

Brightness temperature to land surface temperature was calculated as follows (Weng et al., 2003):

$$
T_{S}=\frac{T_{B}}{1+\left[\frac{\lambda T_{B}}{\partial} \times(\ln \varepsilon)\right]}
$$

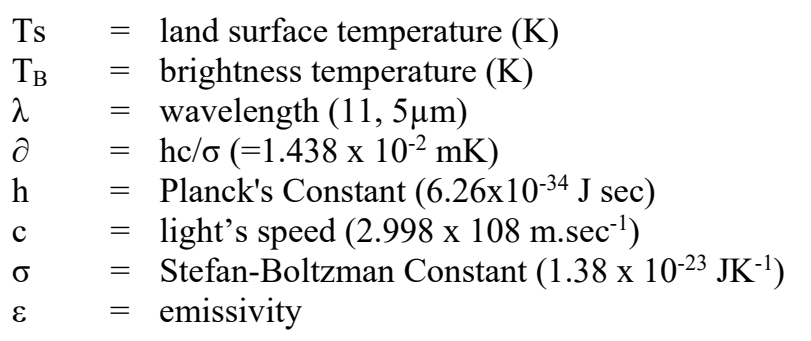


Atmospheric correction by applying equation mentioned in Coll et al. (2010):

$$
\mathrm{L}_{\lambda} "=\left[\frac{\mathrm{L}_{\lambda}-\mathrm{L} \uparrow}{\varepsilon \tau}\right]-\left[\left(\frac{1-\varepsilon}{\varepsilon}\right) L \downarrow\right]
$$

$\mathrm{L}_{\lambda} " \quad=\operatorname{corrected} \mathrm{L}_{\lambda}\left(\right.$ Watts $\left./\left(\mathrm{m}^{2} * \operatorname{srad} * \mu \mathrm{m}\right)\right)$

$\varepsilon \quad=$ emissivity

$\tau=$ transmissivity

$\mathrm{L} \uparrow / \mathrm{L} \downarrow=$ upwelling/ downwelling radiance $\left(\mathrm{Watts} /\left(\mathrm{m}^{2} * \operatorname{srad} * \mu \mathrm{m}\right)\right)$

Emissivity was calculated using the following equation (Urbanski, 2014):

$$
\varepsilon=1.0094+[0.047 \times \ln (\mathrm{NDVI})]
$$

Reflectance value was calculated as follows (Congedo, 2016):

$$
\begin{aligned}
& \text { ESUN }=\left(\pi * d^{2}\right) *[\operatorname{Rad} \max / \text { Ref max }] \\
& \mathrm{L}_{\mathrm{p}}=\left(\mathrm{M}_{\mathrm{L}} * \mathrm{DN}_{\min }\right)+\mathrm{A}_{\mathrm{L}}-0.01 * \mathrm{ESUN}^{*} \cos \theta_{\mathrm{s}} /\left(\pi * \mathrm{~d}^{2}\right) \\
& \rho=\pi * \mathrm{~d}^{2}\left[\mathrm{~L}_{\lambda}-\mathrm{L}_{\mathrm{p}}\right] / \mathrm{ESUN}^{*} \cos \theta_{\mathrm{s}}
\end{aligned}
$$

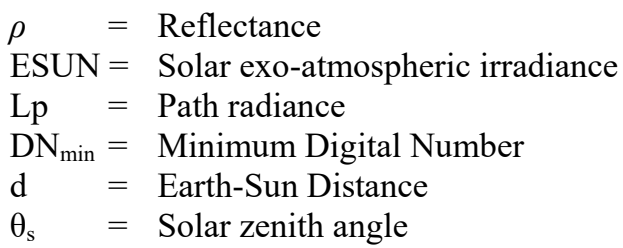

The LST image is visualized in $5^{\circ} \mathrm{C}$ interval value. Two different images then analyzed in order to present how the difference of temperature between two image.

\section{RESULT AND DISCUSSION}

The Geometric correction was not applied to the images because it was conducted systematically from the data provider. However, the two-image acquisition was processed through the whole steps of atmospheric correction before temperature extraction to reduce atmospheric disturbance and improve temperature extraction value in terms of its accuracy.

Normalized Difference Vegetation Index (NDVI) calculated for obtaining emissivity value which used as the input for determining Land Surface Temperature (LST). The NDVI images of 2014 and 2018 classified into the same range. According to the range, it is estimated that the built-up area made up about $49 \%$ and $50 \%$ of the total urban area, respectively, according to those two images. It infers that the built-up area relatively remains unchanged. In other words, urban expansion does not occur. The NDVI results are shown in Figure 3 (a) and (b). According to those images, low NDVI values (approximate to and below 0 (zero) which indicates likely as paved-area) concentrated in the city centre. It is apparent that low NDVI values (in red-orange) depicted along the network line (asphalt road) in both images.

In addition to NDVI, the average emissivity value decreased, from 0.93 in 2014 to 0.88 in 2018 . This result implies that more pixels in 2018 that reflecting the incoming energy compared one in 2014 (Figure 3 (c) and (d)). The emissivity of two images also shown in the histogram in Figure 6 (a) 2014 (b) 2018. According to the histogram's shape. The latter shows shaper bell on the left compared to 2014 image, in order word, flatter and gradually increase steadily compared to one in 2018. This pattern indicates the emissivity value distributes likely to the lower one. In this paper, emissivity value 
is not further discussed as emissivity value depends on the function of wavelength together with temperature. Therefore, emissivity alone is complex to obtain. Therefore, further research is needed, for instance, using an instrument to estimates emissivity value and different time of image acquisition. Emissivity value can be more sensitive. The statistics of emissivity value, as shown in Table 1, with maximum and minimum in 2014 and 2018 value are $0.98 \& 0.65$, and $0.97 \& 0.37$, respectively.
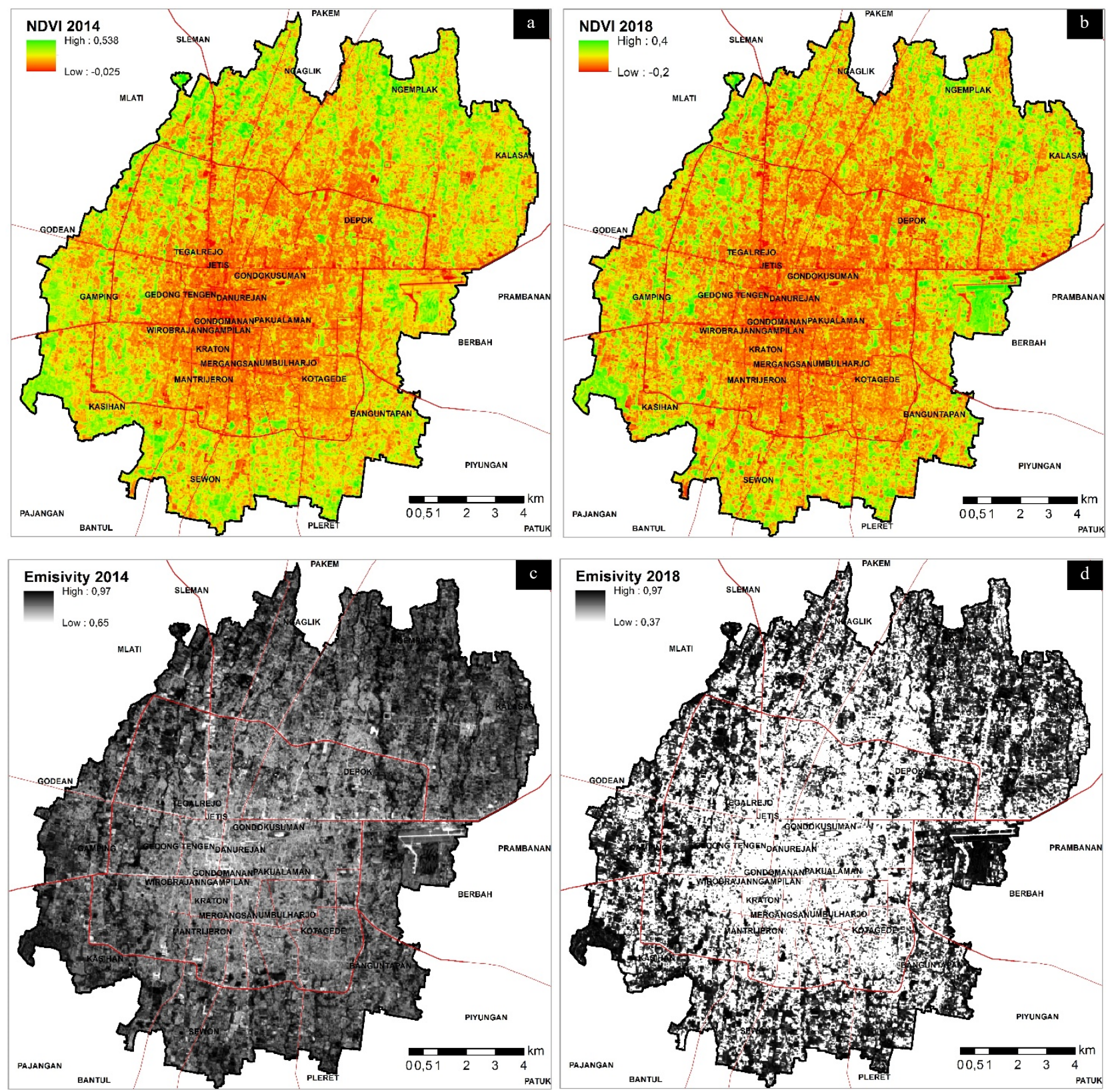

Figure 4. NDVI Value at (a) 2014 and (b) 2018 also Emissivity at (c) 2014 and (d) 2018

The extracted temperature is assumed as "kinetic temperature" since it involved emissivity. The result of temperature extraction shown in Figure 4 (a) and (b). The LST was classified into $5^{\circ} \mathrm{C}$ interval. According to the map, the high LST distributes along the main road along with the concentration of paved-surface. The total study area is 19,662 Ha. Figure (5) shows the statistics of temperature distribution for the two-analyzed images in the classified interval. In 2014, the area with LST around $20-30^{\circ} \mathrm{C}$ was under $1,000 \mathrm{Ha}$. The area with $30-35^{\circ} \mathrm{C}$ is around $5,000 \mathrm{Ha}$. About 7,000 Ha is covered with the surface at temperature ranges from 35 to $40{ }^{\circ} \mathrm{C}$, which makes the most significant proportion of the total area of 
Yogyakarta Urban Area. The area with $40-45^{\circ} \mathrm{C}$ and $45-50{ }^{\circ} \mathrm{C}$ interval occupied around less than $6,000 \mathrm{Ha}$ and 2,000 Ha, consecutively.

According to the 2018 image, the area with 25 to $30^{\circ} \mathrm{C}$ occupies a small area of Yogyakarta Urban Area. The four highest areas occupy the urban area at range $35-40{ }^{\circ} \mathrm{C}, 40-45{ }^{\circ} \mathrm{C}, 30-35^{\circ} \mathrm{C}$, and $45-50{ }^{\circ} \mathrm{C}$, respectively; being $35-40{ }^{\circ} \mathrm{C}$ dominates the surface, reach more than 7,000 Ha. Both images of 2014 and 2018 show that the highest proportion of LST in the study area is around $35-40^{\circ} \mathrm{C}$. Such high-temperature area, more than $50^{\circ} \mathrm{C}$, some reach $95-100^{\circ} \mathrm{C}$. The probable cause of such high temperature might find from asphalt road or the industrial chimneys. Both images also show a similar pattern. It illustrates that the centre of the city has the highest average temperature. The further from the city centre, the higher the temperature. According to the graph, it simply shows that the distribution of pixels with lower temperature tends to shift into higher temperature, comparing 2014 and 2018 image. The histograms, as shown in Figure 7 (a) 2014 (b) 2018 , concede the shifted values aforementioned.

Table 2 represents the statistical value of temperature extraction of both image 2014 and 2018. The average temperature in 2014 was $38^{\circ} \mathrm{C}$, it rose to $39,5^{\circ} \mathrm{C}$ in 2018 . The minimum and maximum value rose by approximately $4{ }^{\circ} \mathrm{C}$ and $18{ }^{\circ} \mathrm{C}$, respectively; while the standard deviation is not considerably changed.
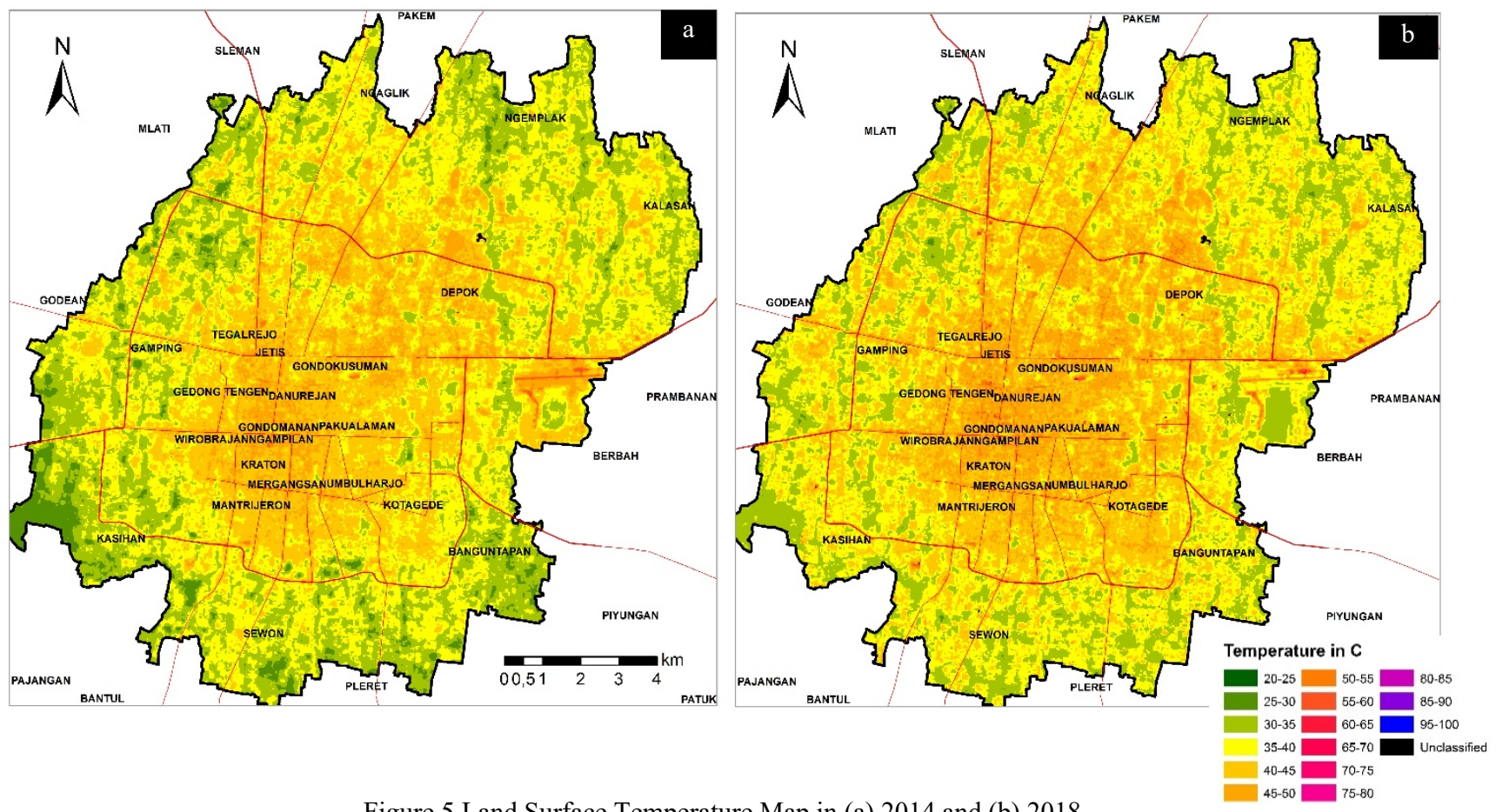

Figure 5 Land Surface Temperature Map in (a) 2014 and (b) 2018

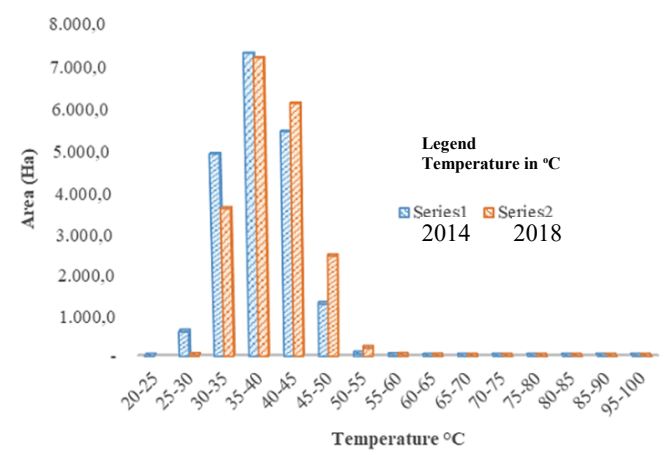

Figure 6. Graph of Changes in Temperature Class Area 
Histograms: Emisivity 2014

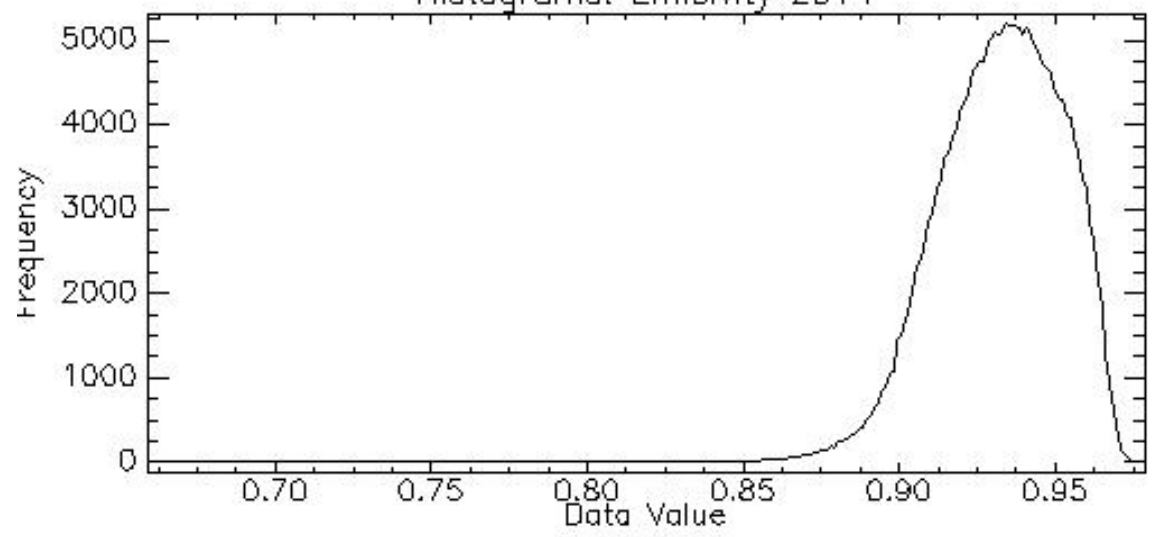

(a)

Histograms: Emisivity 2018

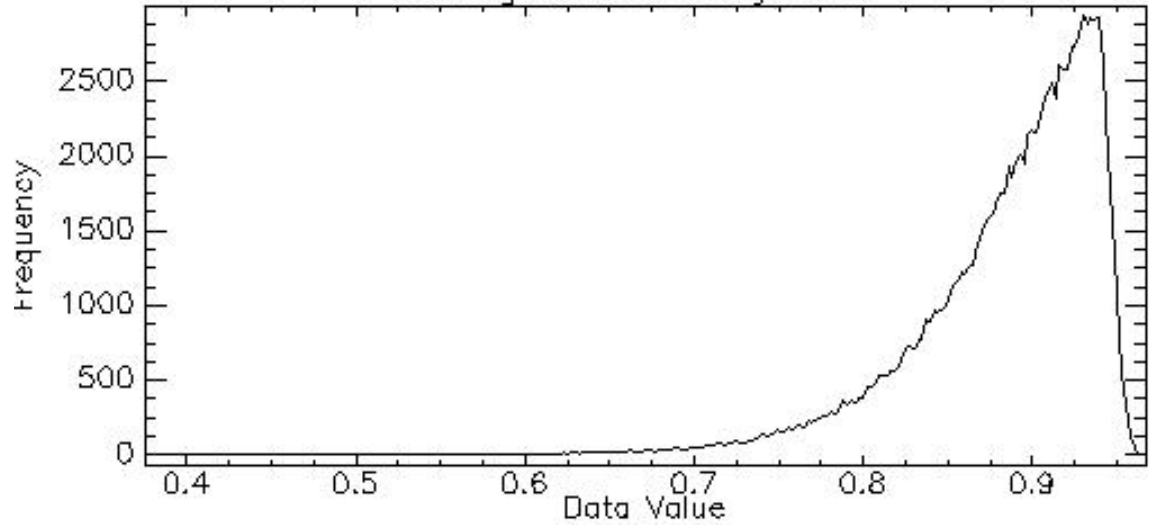

(b)

Figure 7 Histogram of Emissivity (a) 2014 (b) 2018

Table 1. Statistics of Emisivity in 2014 and 2018

\begin{tabular}{|r|r|r|r|r|}
\hline YEAR & \multicolumn{1}{|c|}{ MIN } & \multicolumn{1}{c|}{ MAX } & \multicolumn{1}{c|}{ MEAN } & \multicolumn{1}{|c|}{ STDEV } \\
\hline $\mathbf{2 0 1 4}$ & 0.65 & 0.98 & 0.93 & 0.01 \\
\hline $\mathbf{2 0 1 8}$ & 0.37 & 0.97 & 0.88 & 0.05 \\
\hline
\end{tabular}




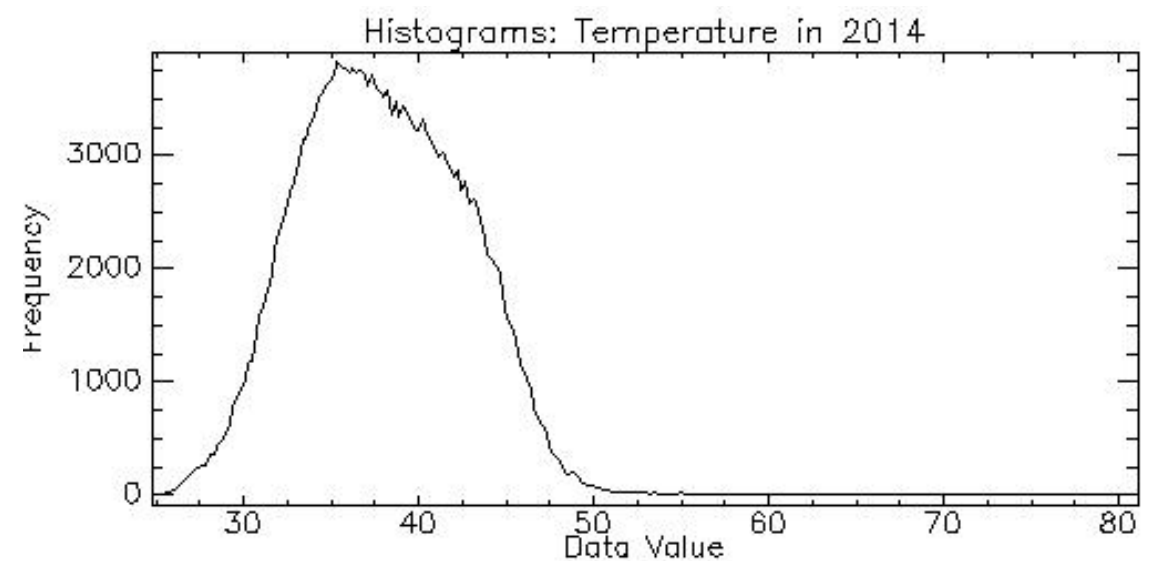

(a)

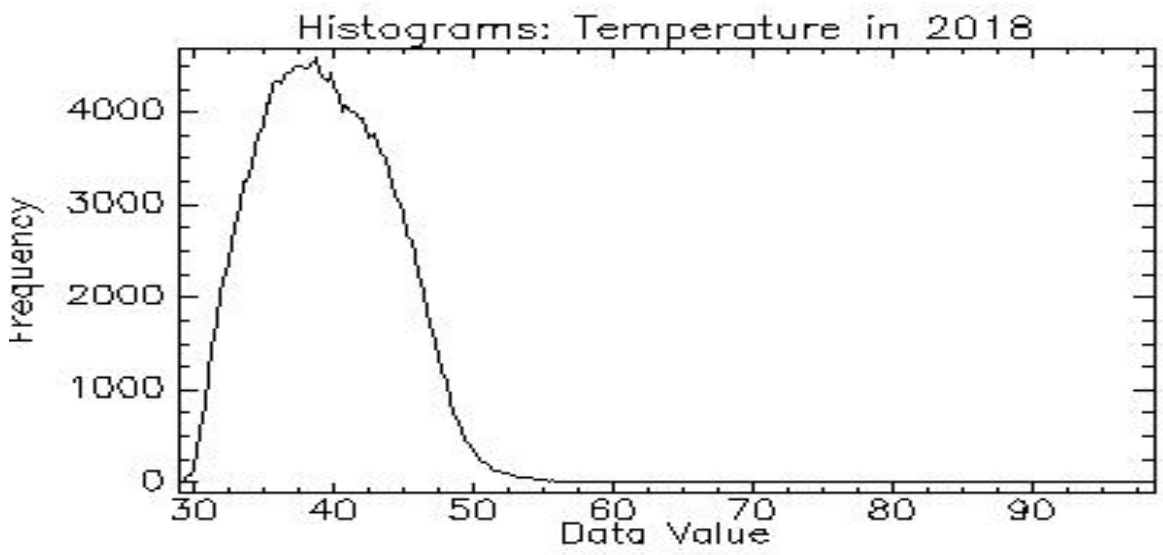

(b)

Figure 8 Histogram of temperature value (a) 2014 (b) 2018

Table 2. Statistics of Land Surface Temperature in 2014 and 2018

\begin{tabular}{|r|r|r|r|r|}
\hline Years & \multicolumn{1}{l|}{ Min } & \multicolumn{1}{l|}{ Max } & \multicolumn{1}{l|}{ Mean } & \multicolumn{1}{l|}{ StDev } \\
\hline $\mathbf{2 0 1 4}$ & 24.75 & 81.1 & 38.04 & 4.62 \\
\hline $\mathbf{2 0 1 8}$ & 28.83 & 98.72 & 39,55 & 4.68 \\
\hline
\end{tabular}

\section{CONCLUSION}

This result shows that the urban area in terms of the built-up area relatively remains unchanged. The average emissivity of both two images of 2014 and 2018 decreases which infers more proportion of reflected energy by the surface in the study area. The temperature tends to increase according to the average land surface temperature (LST). 


\section{REFERENCES}

[1] Coll, C., Joan M. Galve, Juan M. Sánchez., and Caselles,V., "Validation of Landsat-7/ETM+ Thermal Band Calibration and Atmospheric Correction With Ground-Based Measurements." IEEE Transactions On Geoscience And Remote Sensing, Papers 48(1) (2010)

[2] Congedo,L. Semi-Automatic Classification Plugin Documentation. DOI: http://dx.doi.org/10.13140/RG.2.2.29474.02242/1 (2013)

[3] Divigalpitiya, P., Handayani, K. N. (2015). "Measuring the Urban Expansion Process of Yogyakarta City in Indonesia. Urban Expansion Process And Spatial and Temporal Characteristics of Growing Cities." International Review For Spatial Planning And Sustainable Development, Papers 3 (4), 18-32 (2015)

[4] Giyarsih, S. R. "Urban Sprawl of the City of Yogyakarta, Spacial Reference To The Stage of Spatial Transformation." Indonesian Journal of Geography, 42 (1), 47-58 (2010)

[5] IAP. [Indonesia Livable City Index 2014], IAP, Jakarta

[6] Lillesand, T.M., and Kieffer, K.W. [Remote Sensing and Image Interpretation], New York] John Wiley \& Son Inc.

[7] McCarville, D., Buenemann, M., and Bleiweiss,M. "Atmospheric Correction of Landsat Thermal Infrared Data: A Calculator Based on North American Regional Reanalysis (NARR) Data." ASPRS Annual Conference (2011)

[8] Urbanski, J., "Integration of GEOBIA with GIS for Semi-automatic Land Cover Mapping from Landsat 8 Imagery." 5th GEOBIA, (2014)

[9] USGS,'Landsat 8”. http://landsat.usgs.gov/landsat8.php, (01 July 2019)

[10] Weng, Q.,Lub, D., and Schubring,J., "Estimation of land surface temperature-vegetation abunandce relationship for urban heat island studies." Remote Sensing of Environment, 89 (4), 467-483 (2004)

[11] Yang, W., Lin, Y., \& Li, C. Q. "Effects of Landscape Design on Urban Microclimate and Thermal Comfort in Tropical Climate.” Advances in Meteorology, 2018. https://doi.org/10.1155/2018/2809649 (2018) 